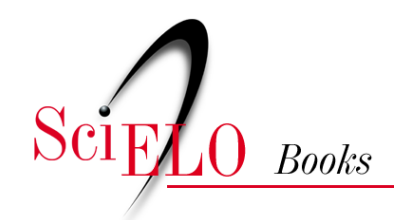

\title{
Entre florestas e parreirais a vitivinicultura no Alto Vale do Rio do Peixe/SC
}

\author{
Eunice Sueli Nodari
}

\section{SciELO Books / SciELO Livros / SciELO Libros}

NODARI, E.S. Entre florestas e parreirais: a vitivinicultura no Alto Vale do Rio do Peixe/SC. In: GERHARDT, M., NODARI, E.S., and MORETTO, S.P., eds. História ambiental e migrações: diálogos [online]. São Leopoldo: Oikos; editora UFFS, 2017, pp. 81-94. ISBN: 978-85-64905-68-9. https://doi.org/10.7476/9788564905689.0006.

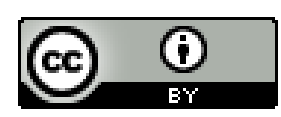

All the contents of this work, except where otherwise noted, is licensed under a Creative Commons Attribution 4.0 International license.

Todo o conteúdo deste trabalho, exceto quando houver ressalva, é publicado sob a licença Creative Commons Atribição 4.0.

Todo el contenido de esta obra, excepto donde se indique lo contrario, está bajo licencia de la licencia $\underline{\text { Creative Commons }}$ Reconocimento 4.0. 


\section{Entre florestas e parreirais: a vitivinicultura no Alto Vale do Rio do Peixe/SC ${ }^{1}$}

Eunice Sueli Nodari

\section{Introdução}

O presente capítulo tem como objetivo discutir aspectos da Vitivinicultura no Alto Vale do Rio do Peixe, tendo como referencial geográfico principal os municípios de Videira, Tangará e Pinheiro Preto, no estado de Santa Catarina.

A produção de vinhos tem sido considerada, a partir do século XX, como uma commodity importante em várias partes do mundo. O interesse para tal se deve tanto ao seu valor comercial, quanto aos seus aspectos simbólicos, culturais e estéticos. Além disso, nas últimas décadas o vinho vem sendo associado às questões de saúde, pois pesquisas demonstraram que ele tem efeitos positivos para prevenir e tratar doenças, como, por exemplo, doenças cardiovasculares, além de estar associado a longevidade (GUILFORD; PEZZUTO, 2011).

A vitivinicultura, como tema de pesquisa, acabou despertando o interesse de geógrafos, economistas, historiadores e mais recentemente de antropólogos, que pesquisam sobre esta commodity em perspectivas locais, regionais e mundiais. Entre os trabalhos que se destacam, tem-se a coletânea de textos na obra intitulada Wine and Culture, em que são discutidos vários temas tais como mercados globais, agencias locais, representações, regiões vinícolas, classes sociais, gênero e os usos da história e da cultura para sustentar a qualidade e a autenticidade do vinho (BLACK; ULIN, 2013).

De acordo com Black e Ulin $(2013$, p. 6), por muito tempo o vinho era considerado somente como uma bebida alcoólica. Desta forma não des-

\footnotetext{
${ }^{1}$ Estes resultados fazem parte do projeto de pesquisa intitulado "Dos vinhedos familiares às grandes empresas: a reconfiguração de paisagens no Brasil através da Vitivinicultura", que conta com o auxílio financeiro do CNPq e Bolsa de Produtividade em Pesquisa do mesmo órgão. É um projeto executado em parceria com Spatial History Project - CESTA/Stanford University.
} 
pertava a atenção para pesquisas de maior folego na área das humanidades. Esta percepção acabava deixando de lado outros aspectos importantes relacionados ao vinho como o ritual, o simbólico e a sua importância social em muitas culturas. Além disso, em muitas sociedades, tanto no passado quanto no presente, o vinho era considerado parte da alimentação, sendo uma importante fonte de calorias. Os autores argumentam que em vários países da Europa o vinho está sempre presente junto com a água nas mesas de almoço e jantar e, muito raramente, é consumido fora das refeições (BLACK; ULIN, 2013).

Assim como em outros países, os estudos no Brasil sobre o tema ainda são escassos nas áreas das ciências sociais e humanas. Isto não significa que a viticultura não esteve presente no Brasil, pois desde o início da colonização portuguesa ocorreu a introdução da uva e a consequente produção de vinhos. Todavia, de forma mais ampla, somente no inicio do século XX, acabou se tornando uma importante atividade industrial e comercial. A concentração dos vinhedos e das industrias inicialmente ocorreu no Sul e no Sudeste e, gradativamente, foi se expandindo para outras regiões como alternativa econômica.

\section{A Vitivinicultura no Brasil}

Se compararmos a vitivinicultura brasileira com outros países mais tradicionais na produção de vinhos, observamos que ela é bem diferenciada e tem características distintas. Segundo Camargo et al., a marca da viticultura brasileira é a sua diversidade: as diferentes condições ambientais, variados sistemas de cultivo e os recursos genéticos com ampla variedade. O cultivo está difundido desde o Rio Grande do Sul, a $31^{\circ} \mathrm{S}$ de latitude, até o Rio Grande do Norte e Ceará a $05^{\circ} \mathrm{S}$ de latitude. Existe também uma grande variedade de altitude, gerando uma considerável diversidade de ambientes entre as zonas de produção, com regiões de clima temperado, subtropical e tropical (CAMARGO et al., 2011, p. 145).

Desta forma, a expansão deu-se em três biomas: na Mata Atlântica, no Pampa (RS) e na Caatinga (Vale do São Francisco) no Nordeste do Brasil. A maior produção de uvas, de vinhos e derivados se concentra na Serra Gaúcha, no bioma Mata Atlântica, onde desde a vinda dos primeiros imigrantes italianos, na década de 1880, começou o cultivo de videiras e o processamento do vinho. Maestri, em seus estudos, mostra que desde o seu 
estabelecimento nas colônias do Rio Grande do Sul, os imigrantes italianos estavam organizando os seus pomares, onde os parreirais apareciam em destaque (MAESTRI, 2005, p. 87).

No bioma Pampa, fronteira com o Uruguai, onde antes os campos eram ocupados pela pecuária e cultivo de grãos como soja e arroz, agora estão cedendo gradativamente espaço também para a vitivinicultura. $\mathrm{Na}$ Caatinga, mais especificamente, no Vale do Rio São Francisco, os vinhos são produzidos nas vinícolas instaladas em municípios pernambucanos e baianos. O Vale se transformou em um polo de desenvolvimento tecnológico da fruticultura irrigada. É importante mencionar que o crescimento do setor vitivinícola no Brasil se deu com apoio governamental, assim como de instituições de pesquisa, de qualificação de mão de obra, de representação de trabalhadores e do setor vinícola (POLITA, 2006, p. 143).

A nossa região de estudo, foco da primeira etapa do projeto, está localizada no clima temperado que se caracteriza por um ciclo anual, seguido por um período de dormência induzido pelas baixas temperaturas do inverno. É a viticultura tradicional no Sul e em regiões de altitude do Sudeste do Brasil, nos Estados do Rio Grande do Sul, Santa Catarina, Paraná, São Paulo e Minas Gerais. Enquanto que nas áreas de clima subtropical têm-se invernos amenos e curtos, mas sujeitos a geadas, assim com um período de dormência natural em junho e julho, ela pode ser trabalhada de forma tradicional, similar ao clima temperado. A viticultura tropical ocorre em regiões onde não existem temperaturas mínimas baixas suficientes para induzir a videira à dormência. Com o crescimento contínuo e uso da tecnologia, podem-se obter duas ou mais colheitas por ano no mesmo vinhedo. Os principais polos são o Vale do Submédio São Francisco, o noroeste paulista e o norte de Minas Gerais (CAMARGO et al., 2011, p. 145).

Todavia, independente da região onde os parreirais foram montados, assim como toda a estrutura industrial para a fabricação do vinho, ocorreram alterações drásticas no meio ambiente. As áreas de clima temperado, após um exaustivo e destrutivo extrativismo das enormes florestas nativas, passaram pela policultura, e, no decorrer das décadas, algumas áreas se tornaram referência na fruticultura com destaque especial à vinicultura.

De acordo com Valduga, a vitivinicultura no Vale dos Vinhedos, assim como em toda a Serra Gaúcha, fortaleceu-se no decorrer do século XX, tornando-se fonte de crescimento regional (VALDUGA, 2007, p. 84). A pesquisadora Ivanira Falcade, em sua tese de doutorado, fez uma análise 
das regiões onde já foram demarcadas, para as indicações de procedência do Vale dos Vinhedos, Pinto Bandeira e Monte Belo (RS), assim como o uso da paisagem vitícola como imagem espacial dos seus vinhos (FALCADE, 2011).

Observa-se, através de dados oficiais que as áreas cultivadas no Brasil, em fase de frutificação, estavam em ascensão entre os anos de 1948 a 1952. Em 1948 apresentavam uma área de 34.654 hectares e já em 1952 uma área de 40.565 hectares (IBGE, 1953). Na década de 1990, os dados mostram as áreas destinadas a colheita com os seguintes números: nos anos de 1997/1998, um total de 56.882 hectares, e nos anos de 1999/2000, um total de 59.379 hectares (EPAGRI, 2000, p. 99).

\section{O Alto Vale do Rio do Peixe: entre o passado tradicional e o futuro inovador}

A vitivinicultura mais expressiva economicamente, em Santa Catarina, está localizada na Região do Alto Vale do Rio do Peixe, que abrange vários municípios. A viticultura desta região apresenta grande similaridade com a da região da Serra Gaúcha quanto a estrutura fundiária, topografia e tipo de exploração vinícola. A mão de obra geralmente é familiar, e volta-se à produção de uvas destinadas principalmente à elaboração de vinhos de consumo corrente e suco de uva, sendo uma parte menor da produção destinada ao consumo in natura (PROTAS et al., 2002). A vitivinicultura do Alto Vale do Rio do Peixe é responsável por cerca de $80 \%$ da produção de uva e vinho no estado, mantendo sua tradição atrelada às origens de seus habitantes, como ocorre na Serra Gaúcha. Grande parte dos produtores e industriais tem ascendência italiana e que migraram para a região oriundos do Rio Grande do Sul e do sul de Santa Catarina. Ao se estabelecerem na propriedade, traziam consigo mudas de parreiras que eram plantadas para produção de consumo próprio.

Santa Catarina, em comparação ao Rio Grande do Sul, teve um processo mais tardio em relação à produção de vinhos de alta qualidade para o mercado consumidor. A partir da década de 1990, os vinhedos localizados na região em estudo, têm o acompanhamento de equipes de pesquisa da Empresa de Pesquisa Agropecuária e Extensão Rural de Santa Catarina EPAGRI, das Estações Experimentais de Videira e de São Joaquim. As condições climáticas de Santa Catarina, aliadas a latitude e locais com alti- 
tudes superiores a 1.000 metros acima do nível do mar, podem ser alguns dos principais responsáveis pelo cultivo de uvas que permitem a elaboração de "vinhos diferenciados por sua intensa coloração, definição aromática e equilíbrio gustativo" (ROSIER, 2003, p. 137).

O futuro da vitivinicultura no Oeste Catarinense já era discutido nos periódicos da região na década de 1930. Augusto Dal Cortivo, contabilista e correspondente de vários jornais, entre eles o Correio do Povo, residente em Caxias do Sul, propôs-se, em 1936, a prestar assessoria por um período de 6 meses, afirmando que "os municípios de Cruzeiro (Joaçaba), Campos Novos, Concordia e Caçador possuem solo e clima próprios para a videira, conforme provas colhidas e pareceres de habilitados técnicos na matéria" (CRUZEIRO, 17 maio 1936, p. 1). O autor do artigo ainda sugere a união dos prefeitos dos 4 municípios, assim como a contratação de um enólogo para percorrer a região "fornecendo instruções práticas aos colonos, quanto à escolha de terras para as novas plantações e seu preparo [...] quais as castas mais apropriadas, para vinho ou para uvas; preparo da cantina e vasilhame, fabricação de vinho, sua conservação, etc.[...] (CRUZEIRO, 17 maio 1936, p. 1).

É interessante observar que, com o apoio dos prefeitos, com presença de representantes do judiciário, do legislativo, assim como do setor terciário e eclesiástico, Augusto Dal Cortivo realizou uma serie de conferências em uma "Campanha Pró-Vitivinicultura no Oeste Catarinense" (A NOTICIA, 28 nov. 1936). O público-alvo maior eram os agricultores.

Na palestra realizada em Caçador, no dia 29 de julho de 1936, o palestrante versou sobre a situação atual e as expectativas para o futuro da região do Oeste. O autor, segundo a reportagem, fez uma análise da indústria e do comércio de madeira e "analisando a sua marcha, os seus lucros e o seu futuro comparados com a vitivinicultura, frisando que a devastação dos pinheirais caminha a passos agigantados e a vida econômica do município ficará fortemente abalada, se não se procurar nova fonte de renda; afirmou que uma videira racionalmente cultivada dura de 50 a 70 anos". Por ocasião da referida palestra, realizada em Caçador, a prefeitura doaria "como prêmio, ao que montar um parreiral de 2.000 videiras, dentro da técnica, 50 hectares de terra" (A NOTICIA, 11 ago 1936, p. 1).

Ao falar sobre os pinheirais, Augusto Dal Cortivo sabia muito bem que isto iria acontecer, pois já tinha observado o mesmo na região de Caxias do Sul, onde o desmatamento foi anterior e fez com que novas alternativas fossem encontradas, sendo que uma delas, para utilizar o solo desmatado e 
com declive, foi a vitivinicultura. No decorrer da década de 1940, a região estava em plena fase do extrativismo vegetal, onde as florestas iam sucumbindo, cedendo espaço a diferentes cultivos, de subsistência, entre elas a vinicultura.

O município de Videira, criado em 31 de outubro de 1943, pelo Decreto-lei 941, foi desmembrado de Campos Novos e "deve o nome ao fato de ser um grande centro vitivinícola do Estado" (ENCICLOPEDIA, 1959, p. 399-400). De acordo com diversas fontes, a primeira plantação de parreiras aconteceu em 1913, com ramos que o senhor Giovanni Crestani trouxe de Urussanga. Outro descendente de italianos, Antonio Ferlin, formou, em 1920, um parreiral com 10.000 mudas de uvas Isabel. A Figura 1 é uma representação fotográfica de parreirais em Perdizes (Videira/SC), um testemunho do cultivo da uva naquela região em 1927. Já na década de 1940, na produção agrícola se destacavam o milho, o trigo e a uva. Neste mesmo período, o município tinha "sete grandes cantinas vinícolas, além de outras pequenas, em poder dos próprios colonos que fabricam o vinho para o seu uso diário" (SILVA, 1950, p. 127). Atualmente, o município de Videira tem uma população de 47.188 pessoas e uma área de $377,9 \mathrm{~km}^{2}$ (IBGE, 2011), bem diferente daquela na época da criação do município, quando contava com $938 \mathrm{~km}^{2}$, fruto do desmembramento de outros municípios.

Figura 1: Vista parcial de Perdizes

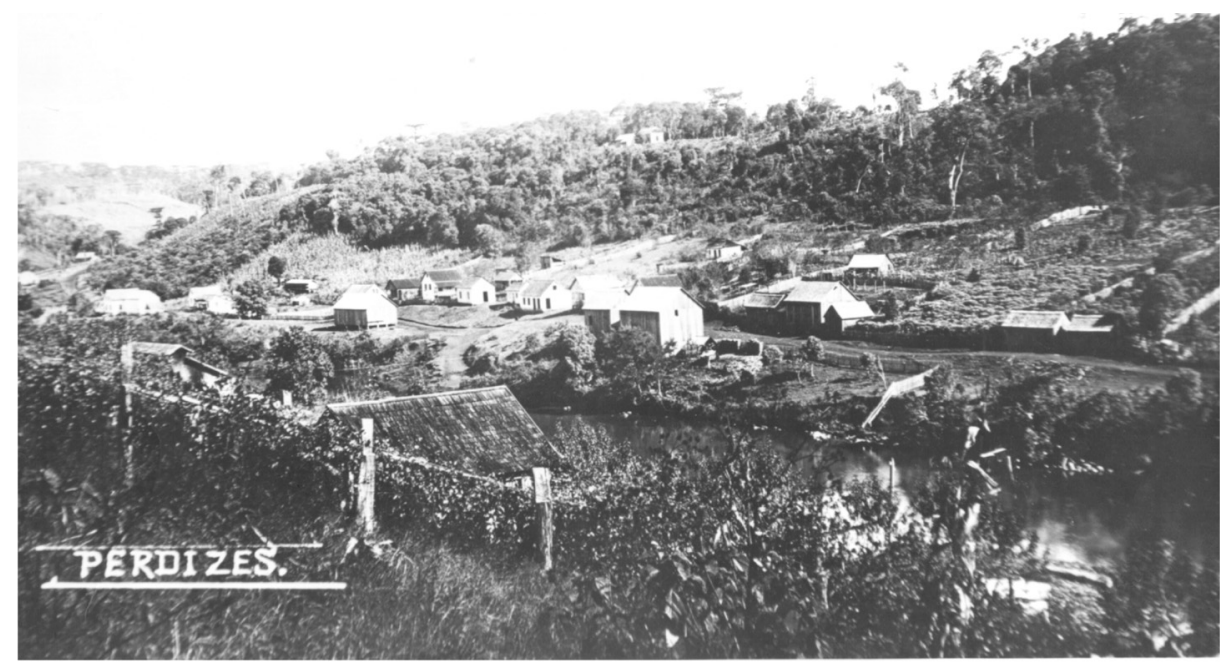

Fonte: Acervo do Museu da Uva e do Vinho. Videira/SC 
O município de Pinheiro Preto foi criado em 1962, desmembrado de Videira, em sua maior parte. É um município com uma área pequena de $65,7 \mathrm{~km}^{2}$ e uma população de 3.147 pessoas, de acordo com o censo de 2010 (IBGE, 2011). Na época de sua criação, foi mencionado que era "o maior produtor de uva de mesa da região, produzindo ainda uva para vinho" [...] A principal empresa à época dedicada ao ramo era a Irmãos Bressan S.A., fundada em 1948, tendo como sócios fundadores Ernesto Bressan e Reynaldo Bressan (SILVA, 1950, p. 183-185).

O município de Tangará teve origem com a construção da estrada de ferro São Paulo - Rio Grande na década de 1910. A maioria dos moradores eram oriundos do Rio Grande do Sul, que se instalaram em pequenas propriedades, como era o padrão de colonização no Oeste de Santa Catarina (NODARI, 2009). A sua primeira denominação foi Rio Bonito, distrito de Videira. Passa a município, através da Lei n. 247, de 30 de dezembro de 1943, recebendo o nome de Tangará (ENCICLOPEDIA, 1959, p. 362). Na época da sua criação tinha uma área de $631 \mathrm{~km}^{2} \mathrm{e}$, com o desmembramento de outros distritos, atualmente está limitado a $389,19 \mathrm{~km}^{2}$ e uma população de 8.748 habitantes (IBGE, 2011).

Segundo Silva, que enaltece a região Oeste em suas escritas, no município de Tangará se observava o seu progresso: "as suas montanhosas e fertilíssimas terras - outrora cobertas de densas florestas - produzem trigo, cevada, linho, milho, feijão, vinhas, etc.". Ainda no mesmo texto é mencionado que "extensos vinhedos cobrem grande área do território do município, e a eles dedica o colono uma atenção toda especial, dado o conhecimento profundo que tem desse importante ramo da atividade rural" (SILVA, 1950, p. 138).

De acordo com dados do IBGE, na década de 1950, a economia tinha a sua base na agricultura, na pecuária e na silvicultura. Nas culturas temporárias, "segundo a importância, temos: trigo, milho, cevada, abóbora, alfafa, feijão (grão), batata-doce, linho, palha, mandioca, aipim, cana de forragem, batatinha, arroz, fumo em fôlha, aveia (grão), linho (semente), melancia, alho, tomate, centeio, ervilha, amendoim com casca, fava; nas culturas permanentes se destacava a uva, seguido de figo, laranja, pêra, maçã, marmelo, pêssego, bergamota, caqui e limão. O extrativismo vegetal ainda tem destaque, interessante é que consta a colheita e venda de $32.000 \mathrm{Kg}$ de pinhão" (ENCICLOPEDIA, 1959, p. 363). 
A produção de vinho neste mesmo período ocorria nas seguintes cantinas: Cantina Vinícola Rio Bonito, Irmão Arcari, Simionato \& Cia., ambas localizadas na cidade de Tangará. Uma das mais antigas cantinas da região do Alto Vale do Rio do Peixe, a Vinícola Rio Bonito S.A., foi fundada em 1934 por um grupo de industrialistas. Possuía uma produção anual de 300 mil litros de vinho, que eram consumidos em Santa Catarina, Paraná e São Paulo (SILVA, 1950, p. 153-154).

Atualmente, uma das vinícolas que se destaca é a Vinícola Panceri, como um típico modelo de empresa familiar e que traz por gerações a arte de vitivinicultura. A imigração familiar da Lombardia para o Brasil deu-se em 1884, quando Giuseppe Panceri se estabeleceu no Rio Grande do Sul. Seu filho Luigi migrou para Santa Catarina, onde intercalou o seu trabalho com a sua fábrica de tecelagem, a agricultura e as videiras. A produção de vinho era para consumo próprio, e o cultivo de uvas era para venda in natura. Em 1990, Nilo Panceri e seus filhos Luiz e Celso fundam a Vinícola Panceri e vão se estabelecendo gradativamente. No ano de 2000 iniciaram o plantio de uvas viníferas, elaborando vinhos de alta qualidade (MARX, 2010, p. 7).

Em entrevista publicada no dia 13 de junho de 2016, Celso Panceri, proprietário da Vinícola Panceri, deixa claro como entende a sua empresa, que é uma extensão da sua família, e como vê o passado, o presente e o futuro:

Eu nasci nesse setor. É um negócio de família. Meu avô e meu pai sempre trabalharam com isso. A única coisa que aprendi foi cultivar uvas e fazer vinhos. Somos descendentes de italianos. A gente conserva as tradições italianas. O vinho está na nossa vida como um filho. A gente até emprestou o nome nosso para os vinhos, Panceri. Tivemos sucesso no setor. A gente vive desse setor. Minhas duas filhas estão estudando, mas já colaboram com o nosso negócio (DIÁRIO CATARINENSE, 13 jun 2016).

Com base neste histórico sobre algumas áreas de produção de uva e fabricação de vinho em Santa Catarina, constata-se que o vinho se torna uma commodity somente no final do século XX e com os apoios dos governos estadual e federal. No Gráfico 1, que abrange a evolução a partir do ano de 1946, análise feita com intervalos de 10 anos, observa-se um aumento de quase $100 \%$ na área cultivada a partir de 1956 , mantida uma certa estabilidade na área de cultivo até as décadas de 1980 e 1990, quando ocorre uma queda brusca. De acordo com pesquisadores da EPAGRI, podem ser apontadas várias causas para este declínio, entre elas a síndrome deno- 
minada declínio e morte de videiras (DMV ou simplesmente declínio) que "contribuiu significativamente para a diminuição da área cultivada. Também contribuíram para essa redução o alto custo de implantação dos vinhedos e o mercado competitivo, que limita a rentabilidade" (MENEZESNETTO et al., 2016, p. 13).

Gráfico 1: Anos e áreas cultivadas no Estado de Santa Catarina

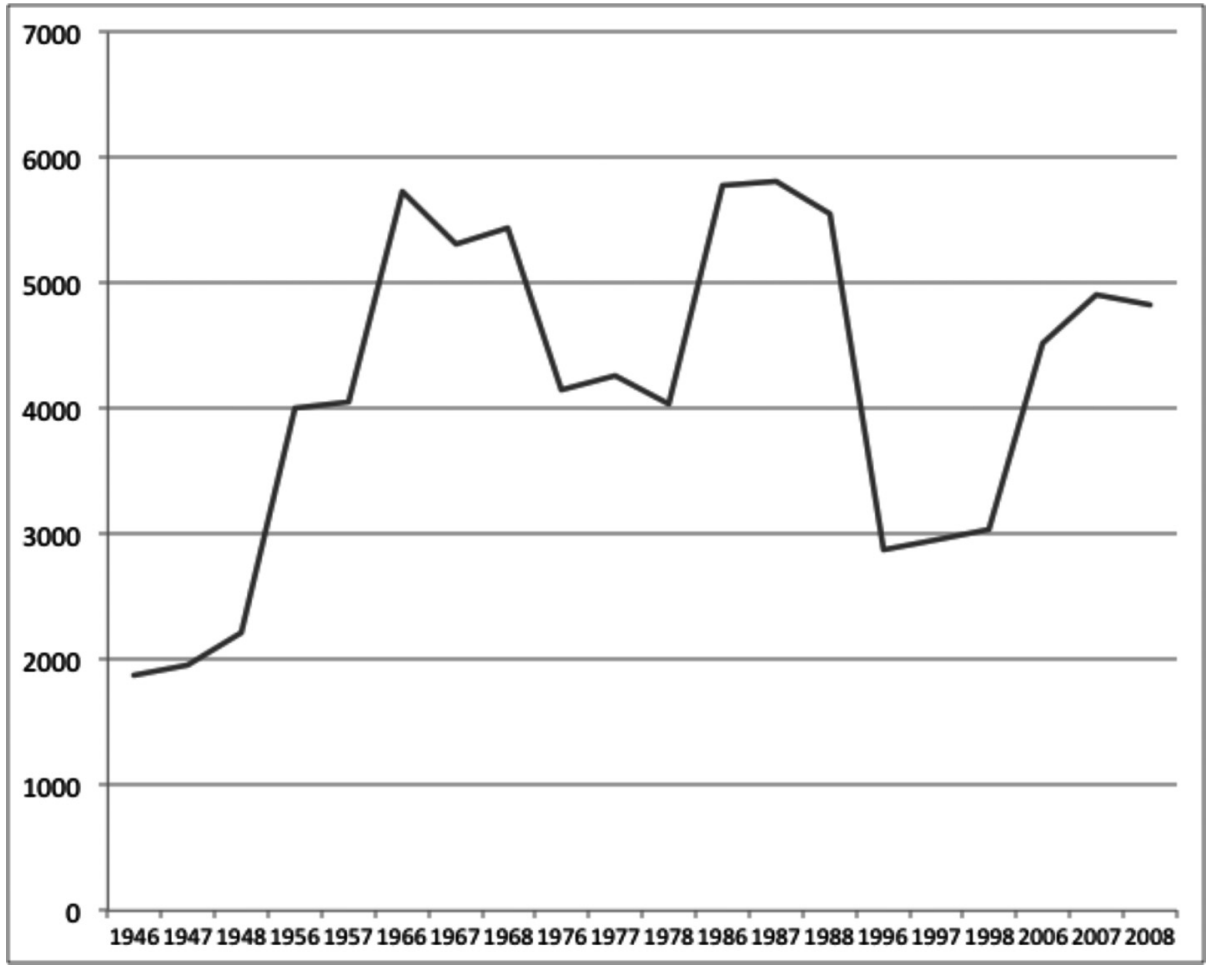

Fonte: IBGE. Instituto Brasileiro de Geografia e Estatística. Anuário estatístico do Brasil, anos 1946 a 2008

As cultivares são geralmente classificadas de acordo com seus produtos finais: videira para vinho, uvas de mesa ou para uva passa (THIS et al., 2006). Outro tipo de categorização conforme o uso refere-se a uvas finas, neste caso variedades da espécie Vitis vinifera, ou uvas rústicas, também denominadas de uvas comuns, cujas variedades pertencem a espécie Vitis labrusca. Na literatura, uvas de mesa podem ser tanto uvas finas como uvas 
comuns. No entanto, é possível encontrar a expressão "uva comum" usada como sinônimo de "uva de mesa":

As uvas podem ser separadas em duas categorias: conforme o uso: de mesa ou comum, normalmente dos cultivares norte-americanas (niagara, isabel) e viníferas, de espécies europeias (cabernet, carmenere, malbec, merlot, pinot noir, syrah, tannat, tempranillo, chardonay, riesling, sauvignon). Há cultivares que se prestam para ambos os fins (EPAGRI, 2013, p. 44).

Entretanto, para a elaboração do gráfico não foi feita esta distinção. A trajetória em busca de vinhos de alta qualidade, feito com uvas finas, contou com o apoio da EPAGRI, na década de 1990, quando os técnicos da empresa incentivaram a implantação de vinhedos de uvas finas na região. De acordo com pesquisadores da EPAGRI, em seus estudos, existem inúmeros fatores e características que devem ser considerados. As características de clima, relevo, cobertura vegetal, manejo dos parreirais, práticas de cultivo, além de aspectos culturais têm influência na tipicidade dos vinhos provenientes das regiões mais altas de Santa Catarina, os chamados vinhos de altitude, produzidos a mais de $900 \mathrm{~m}$ acima do nível do mar (VIANNA et al., 2016, p. 216).

De acordo com levantamentos feitos pela EPAGRI, até 2013, haviam sido implantados 590 vinhedos, com uma área de 332,35 hectares, distribuídos em 13 municípios. Os três municípios que estamos considerando, apresentam poucas propriedades. Implantaram vinhedos em 2013, com a classificação de vinhos de elevada altitude. O município de Videira possuía 2 propriedades, com uma área de 12,84 ha, Tangará, 2 propriedades com 22,18 ha, e em Pinheiro Preto não houve a implantação de nenhum vinhedo de elevada altitude (VIANNA et al., 2016, p. 217-200).

A busca pela qualidade dos vinhos envolve diferentes opções, além de apresentar também um outro perfil de produtores, nem sempre ligados a etnia italiana, nem de serem agricultores antes de iniciar a produção. Ao analisar as principais vinícolas que produzem os vinhos de altitude, Flavia Losso observa:

De maneira geral, são empresários bem sucedidos em outros setores e, por gostarem de vinho (por distintas razões), eles optam por este novo investimento. Porém, somente a paixão pela bebida não seria motivo suficiente para se empreender, e, sim, a oportunidade de ter um bom negócio, inovador que vislumbre a lucratividade e possa desenvolver mais a região economica e culturalmente (LOSSO, 2010, p. 121). 
Até o momento ainda não analisamos o histórico de todas as vinícolas, que contempla a etnia dos proprietários, a tradição familiar na área, a razão da fundação das vinícolas, entre outros aspectos, para podermos confirmar ou contestar a afirmação de Losso. Todavia, podemos mencionar que as principais vinícolas no Rio Grande do Sul tiveram origem em propriedades agrícolas familiares, em sua maioria imigrantes e descendentes de origem italiana e que mais tarde se transformaram em grandes empresas, como por exemplo, a Miolo e a Casa Valduga.

A mudança de paradigmas no modelo de colonização e estabelecimento de vinícolas, de uma forma contradiz os padrões tradicionais. Assim temos os vinhedos de altitude, em regiões com mais de 1000 metros acima do nível do mar, estabelecendo-se em colinas consideradas inviáveis no passado pelos imigrantes. Além disso, existem municípios que apresentam somente parreirais de uvas viníferas. Como exemplo, podemos citar São Joaquim, com uma área de 225,0 hectares em produção, Água Doce, com 52,5, e Bom Retiro, com 45,0 (EPAGRI, 2013, p. 48).

\section{Considerações finais}

A transição de agricultura para a produção e o comércio vinícola vem de uma longa tradição em vários países. Desta rica tradição e de séculos de erros e acertos cresceu a moderna indústria do vinho. Historicamente, as empresas vitivinícolas mais bem-sucedidas foram aquelas que, de alguma forma, reuniram agricultores e vinicultores em empresas verticalmente integradas (GERACI, 2000).

A região em estudo é tipicamente de policultura, em sua maioria composta de pequenas a médias propriedades rurais, onde a vitivinicultura está gradativamente ocupando um espaço importante. Assim como em outras regiões vinícolas, surgem, ao lado ou junto aos vinhedos, lugares de degustação, pousadas, incentivando assim o enoturismo.

Atualmente existem 2.892 produtores, sendo que, deste total, 962 estão estabelecidos no Alto Vale do Rio do Peixe, e os municípios de Videira, Tangará e Pinheiro Preto têm um total de 484 produtores. A maioria da produção nestes três municípios continua sendo de uvas de mesa ou comum, normalmente dos cultivares Niágara e Isabel.

Os vinhos de altitude, produzidos pelas vinícolas, tem como mercado comprador as classes médias e altas, devido ao custo da produção e, 
consequentemente, o valor cobrado. E, por outro lado, as vinícolas que trabalham com vinhos de mesa e sucos também constituem um setor economicamente importante, em razão da crescente demanda.

As paisagens da região já passaram por diferentes fases, sendo que a primeira delas foi o desmatamento em grande escala, no período extrativista, especialmente das florestas com araucárias, que, hoje em pequena quantidade, emolduram os vinhedos.

Provavelmente, outras alterações irão suceder, se levarmos em conta as mudanças climáticas que estão ocorrendo e que colocam a fruticultura, incluindo os vinhedos em clima temperado, em risco nos atuais locais de cultivo. Os parreirais em clima temperado dependem de períodos de frio nos meses de inverno para que haja a produção de uvas de qualidade para a produção de vinhos, dentro do padrão pretendido. A tecnologia nem sempre é suficiente quando envolve aspectos relacionados à natureza, além do fato que o vinho é um produto cultural que exige a intervenção humana em todo o processo.

\section{Referências e fontes}

A NOTÍCIA - Joinville, 28 de novembro de 1936.

A NOTÍCIA - Joinville, 11 de agosto de 1936.

BLACK, Rachel E.; ULIN, Robert C. Wine and Culture: Vineyard to Glass Bloomsbury Academic. London; New York, 2013.

CAMARGO, U. A. et al. Progressos na viticultura brasileira. Revista Brasileira de Fruticultura, Jaboticabal, v. 33, n. especial, p. 144-149, out. 2011.

CRUZEIRO. A vitivinicultura no Oeste Catarinense. Cruzeiro. Cruzeiro/Joaçaba, p. 1, n. 112, 17 mai. 1936.

DIÁRIO CATARINENSE, 13 jun. 2016.

ENCICLOPÉDIA DOS MUNICÍPIOS BRASILEIROS. XXXII vol. Rio de Janeiro: Instituto Brasileiro de Geografia e Estatística, 1959.

EPAGRI. Empresa de Pesquisa Agropecuária e Extensão Rural de Santa Catarina. Fruticultura Catarinense em Números - 2012-2013. Florianópolis, 2013.

EPAGRI. Empresa de Pesquisa Agropecuária e Extensão Rural de Santa Catarina. Sintese Anual da Agricultura de Santa Catarina. Florianópolis: Epagri/Cepa. Anos 1976 a 2008.

EPAGRI. Sintese anual da agricultura de Santa Catarina: 2000-2001. Florianópolis: Instituto Cepa/SC, 2001. 
FALCADE, Ivanira. A paisagem como representação espacial: a paisagem vitícola como símbolo das indicações de procedência de vinhos das regiões Vale dos Vinhedos, Pinto Bandeira e Monte Belo (Brasil). Tese (Doutorado em Geografia), Universidade Federal do Rio Grande do Sul, Porto Alegre, 2011.

GERACI, Victor W. The Family Wine-Farm: Vintibusiness Style. Agricultural History, v. 74, n. 2 (Spring), p. 419-432, 2000.

GUILFORD, Jacquelyn M.; PEZZUTO John M. Wine and Health: A Review. American Journal of Enology and Viticulture. July 2011; DOI: 10.5344/ajev.2011.11013. Disponível em: <http://www.ajevonline.org/content/early/2011/07/26/ ajev.2011.11013>. Acesso em: 25 abr. 2016.

IBGE. Instituto Brasileiro de Geografia e Estatística. Censo demográfico de 2010. Rio de Janeiro, 2011.

IBGE. Instituto Brasileiro de Geografia e Estatística. Anuário estatístico do Brasil, 1946 a 2008.

IBGE. Instituto Brasileiro de Geografia e Estatística. Produção Agrícola MunicipalSanta Catarina. 1976 a 2008.

IBGE. Instituto Brasileiro de Geografia e Estatística. Anuário estatístico do Brasil. Rio de Janeiro: IBGE, 1953.

LOSSO, Flavia Baratieri. A produção de vinhos finos de altitude na região vitivinicola de São Joaquim/SC: Uma alternativa para o Turismo? Dissertação (Mestrado em Turismo e Hotelaria), Universidade do Vale do Itajaí, 2010.

MAESTRI, Mário. Os senhores da serra: a colonização italiana do Rio Grande do Sul 1875-1914. 2 ed. rev. e ampliada. Passo Fundo: UPF, 2005.

MALINOVSKI LI et al. 2012. Highlands of Santa Catarina/Brazil: a region with high potential for wine production. Acta Horticulturae 931, p. 433-440.

MARX, Naira. Relatório de Estágio Vinícola Panceri-safra 2010. Trabalho de Conclusão de Curso Superior. Instituto Federal de Educação, Ciência e Tecnologia do Rio Grande do Sul - Campus de Bento Gonçalves, 2010.

MENEZES-NETTO, A. C.; SOUZA, A. L. K.; ARIOLI, C. J.; SOUZA, E. L.; HICKEL, E. R.; ANDRADE, E. R.; SCHUCK, E.; ARAUJO FILHO, J. V.; GARDIN, J. P. P.; DALBÓ, M. A.; DAMBROS, R. N. Declinio e morte de videiras no estado de Santa Catarina: causas e alternativas de controle. Florianópolis: Epagri, 2016. (Boletim Técnico, 175).

NODARI, Eunice Sueli. Etnicidades renegociadas: práticas socioculturais no Oeste de Santa Catarina. Florianópolis: Editora da UFSC, 2009.

POLITA, Fabíola S. O processo de desenvolvimento do Vale dos Vinhedos. Dissertação (Mestrado em Desenvolvimento Regional), Unijuí, Ijuí, 2006. 
PROTAS, J. F. S.; CAMARGO, U. A.; MELLO, L. M. R. A vitivinicultura brasileira: realidade e perspectivas. Bento Gonçalves: Embrapa-CNPUV, 2002, Artigos Técnicos. Disponível em: <http://www.cnpuv.embrapa.br/publica/artigos/ vitivinicultura/>. Acesso em: 25 abr. 2016.

PROTAS, J. F. S. A marca coletiva como estratégia organizacional: o caso dos vinhos de altitude de Santa Catarina. Bento Gonçalves: Embrapa Uva e Vinho, 2012. (Documentos, 77).

ROSIER, Jean Pierre. Novas regiões: vinhos de altitude no sul do Brasil. In: Anais $\mathrm{X}$ Congresso Brasileiro de Viticultura e Enologia [e do] Seminário CYTED: Influência da Tecnologia Vitícola e Vinícola na Cor dos Vinhos / Editado por Mauro Celso Zanus, Olga Laureano, George Wellington Bastos de Melo e Sandra de Souza Sebben. Bento Gonçalves, RS: Embrapa Uva e Vinho, 2003.

ROSIER, J. P. Vinhos de altitude: característica e potencial na produção de vinhos nos brasileiros. Informe Agropecuário, n. 27, p. 105-110, 2006.

SANTA CATARINA. Síntese Anual da Agricultura de Santa Catarina: anos 2000-2001. Florianópolis, 2001.

SILVA, Zedar P. da (Coord.). Oeste Catarinense. Rio de Janeiro: Gráfica Laemmert Ltda, 1950.

THIS, P.; LACOMBE, T.; THOMAS, M. R. Historical origins and genetic diversity of wine grapes. Trends in Genetics, v. 22, n. 9, p. 511-519, 2006.

VALDUGA, Vander. O processo de desenvolvimento do enoturismo no Vale dos Vinhedos. Dissertação (Mestrado em Turismo), Universidade de Caxias do Sul, 2007.

VIANNA, L. F. N.; MASSIGNAN, A. M.; PANDOLFO, C.; DORTZBACH, D.; VIEIRA, V. F. Caracterização agronômica e edafoclimática dos vinhedos de elevada altitude. Revista de Ciências Agroveterinárias, v. 15, p. 215-226, 2016. 